\title{
Phosphate monoesterase and diesterase activities in the North and South Pacific Ocean
}

\author{
M. Sato ${ }^{1}$, R. Sakuraba ${ }^{2}$, and F. Hashihama ${ }^{2}$ \\ ${ }^{1}$ Graduate School of Agricultural and Life Sciences, University of Tokyo, Tokyo, Japan \\ ${ }^{2}$ Tokyo University of Marine Science and Technology, Tokyo, Japan \\ Correspondence to: M. Sato (asatom@mail.ecc.u-tokyo.ac.jp)
}

Received: 6 June 2013 - Published in Biogeosciences Discuss.: 20 June 2013

Revised: 18 October 2013 - Accepted: 23 October 2013 - Published: 27 November 2013

\begin{abstract}
Phosphate monoesterase and diesterase activities were measured with soluble reactive phosphorus (SRP) and labile and total dissolved organic phosphorus (DOP) concentrations in the North and South Pacific Ocean, to reveal the microbial utilization of phosphate esters in the Pacific Ocean. Both esterase activities were noticeably enhanced around the western part of $30^{\circ} \mathrm{N}$, where the surface SRP concentration was below $10 \mathrm{nM}$, while they showed no significant correlation with DOP concentration. The proportion of the activity in the dissolved fraction was higher for diesterase than monoesterase, which may support results from previous genomic analyses. Substrate affinity and the maximum hydrolysis rate of monoesterase were the highest at lower concentrations of SRP, showing the adaptation of microbes to inorganic phosphorus nutrient deficiency at the molecular level. The calculated turnover time of monoesters was 1 to 2 weeks in the western North Pacific Ocean, which was much shorter than the turnover time in other areas of the Pacific Ocean but longer than the turnover time in other phosphate-depleted areas. In contrast, the turnover rate of diesters was calculated to exceed 100 days, revealing that diesters in the western North Pacific were a biologically refractory phosphorus fraction. In the present study, it was revealed that both phosphate monoesters and diesters can be a phosphorus source for microbes in the phosphate-depleted waters, although the dynamics of the two esters are totally different.
\end{abstract}

\section{Introduction}

Phosphorus is essential for every living system (Karl, 2000), and it is present in nucleic acids, adenosine triphosphate, and phospholipids. Inorganic phosphate, the biologically most accessible form of phosphorus, is often very scarce in the pelagic environment (Wu et al., 2000; Karl et al., 2001).

When the inorganic phosphorus pool is deficient, aquatic microbes can access the dissolved organic pool by direct uptake or indirect uptake after an enzymatic reaction. Dissolved organic phosphorus (DOP) is composed of various compounds with different chemical properties, and phosphate esters and phosphonates are the major components (Kolowith et al., 2001). Phosphate esters are characterized by their PO bonds where the esters are hydrolyzed to inorganic phosphate. Alkaline phosphatase, which can hydrolyze phosphate esters, are produced by many aquatic microbes, and its activity has been used as an index of phosphorus deficiency or stress (Hoppe, 2003). Phosphate esters are categorized into monoesters, diesters, and triesters according to the number of ester bonds. Studies on phosphate esters in seawater have focused on monoesters, but a few studies showed that the concentration of phosphate diesters in surface water can be sometimes comparable with that of monoesters (Suzumura et al., 1998; Monbet et al., 2009), suggesting the potential importance of diesters as a phosphorus source for microbes. Indeed, some marine phytoplankton species can produce phosphate diesterase and grow on phosphate diesters as their sole phosphorus source (Yamaguchi et al., 2005). Recently, reports have demonstrated the use of other components of DOP by aquatic microbes, including phosphonates (Dyhrman et al., 2006; Ilikchyan et al., 2010) and phosphite (Martínez et al., 2012). 
The North and South Pacific subtropical gyres are oligotrophic, low productive areas, characterized by contrasting phosphorus environments. In the western part of the North Pacific subtropical gyre, surface soluble reactive phosphorus (SRP), which consists mainly of inorganic phosphate, is exhausted down to < $3 \mathrm{nM}$ (Hashihama et al., 2009), while its concentration in the South Pacific subtropical gyre is higher than $100 \mathrm{nM}$ (Moutin et al., 2008). Despite the importance of revealing biogeochemical phosphorus cycling across these contrasting phosphorus regimes, studies have generally been concentrated in the South Pacific (Moutin et al., 2008; Duhamel et al., 2011) and the central part of the North Pacific near Hawaii (Björkman et al., 2000; Brum, 2005). Recently, a few reports on alkaline phosphatase activities from the western North Pacific near Japan (Suzumura et al., 2012; Girault et al., 2013) suggested strong phosphate deficiency in this area. However, data sets on phosphorus cycling across different ocean basins are still scarce. Additionally, there have been few reports on cycling or utilization of phosphate diesters except for dissolved DNA (Paul et al., 1987; Jørgensen and Jacobsen, 1996; Brum, 2005) or RNA (Björkman et al., 2000), a polymer of phosphate diesters, although phosphate diesters are potentially as important a phosphorus source as monoesters in the natural water.

Therefore, in the present study, we conducted cross-basin observations of phosphatase activities in the Pacific Ocean, with emphasis on the North and South Pacific subtropical gyres, to compare the biogeochemical cycles of phosphorus in these gyres. Moreover, we measured the phosphate diesterase activities in the western North Pacific to elucidate the potential of phosphate diesters as a phosphorus source to microbes. At some stations, kinetic experiments were conducted to estimate potential turnover times of phosphate monoesters and diesters. From these results, some important aspects of phosphorus cycling in the pelagic water of the $\mathrm{Pa}$ cific Ocean were revealed.

\section{Materials and methods}

\subsection{Sampling}

Sampling and bioassay experiments were conducted during the following two cruises on the R/V Hakuho-maru, KH11-10 (December 2011-January 2012) and KH-12-3 (JulyAugust 2012), (Fig. 1 and Table 1). At each station, seawater was collected from depths of $10 \mathrm{~m}$ and subsurface chlorophyll maximum (SCM) layer by using Niskin-X samplers mounted on a carousel equipped with a conductivity, temperature and depth (CTD) sensor. The SCM depth was determined according to an in situ chlorophyll fluorescence profile obtained by a fluorometer equipped with a CTD sensor. When the SCM was not obvious, the sample was taken from the bottom of the surface mixed layer.

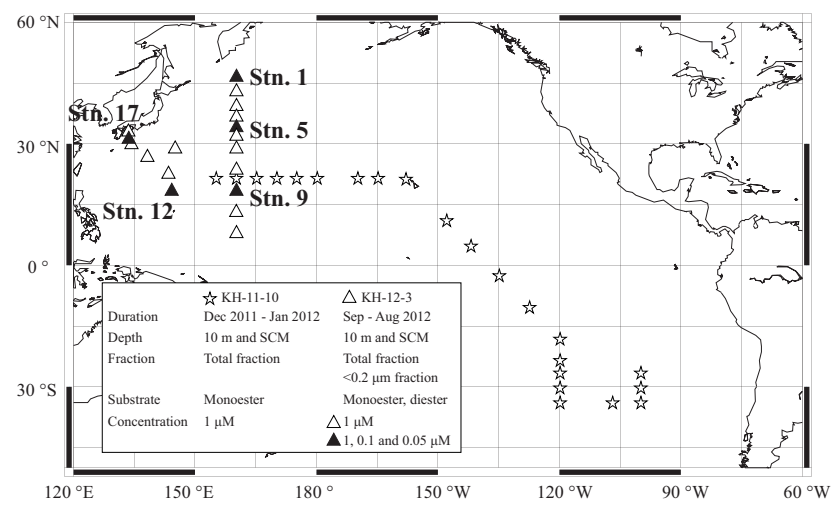

Fig. 1. Station location. Different symbols indicate different cruises. Kinetic assay experiments were conducted at the five stations indicated by solid symbols.

Seawater samples for the measurement of enzymatic activities were dispensed into $125 \mathrm{~mL}$ black polyethylene bottles and stored in the incubator set at the temperature of the $10 \mathrm{~m}$ depth. Samples for SRP, labile DOP (LDOP), and total DOP were collected in $30 \mathrm{~mL}$ polypropylene tubes. During the KH-12-3 cruise, only LDOP samples were collected in duplicate. For the sample collection of the total DOP, seawater was first filtered using a precombusted Whatman GF/F filter. All the sample containers had been washed thoroughly with Milli-Q water after soaking in dilute $\mathrm{HCl}$.

\subsection{Monoesterase and diesterase activity assay}

During the KH-11-10 cruise, only monoesterase activity (MEA) in the total (unfiltered) fraction was measured, while during the KH-12-3 cruise, MEA and diesterase activity (DEA) in both the total and dissolved $(0.2 \mu \mathrm{m}$ filtered) fractions were measured at all the stations.

MEA and DEA were assayed using substrates with fluorescent moieties (Hoppe, 1983), 4-methylumbelliferyl phosphate (MUP, Invitrogen) and bis (4-methylumbelliferyl) phosphate (Bis-MUP, Chem-Impex International), respectively. Stock solutions $(50 \mu \mathrm{M})$ of the fluorescent substrates were prepared in an autoclaved $3.5 \% \mathrm{NaCl}$ aqueous solution. The MUP stock was stored in a refrigerator when not in use. Since Bis-MUP gradually hydrolyzes in the stock solution at $4{ }^{\circ} \mathrm{C}$, it was divided into small aliquots and stored in liquid nitrogen.

For enzymatic assay experiments, $2.5 \mathrm{~mL}$ of seawater was dispensed into an acrylic $1 \mathrm{~cm}$ cell and the fluorescence was measured. Experiments were run in triplicate for all the experimental groups. Filtered $(<0.2 \mu \mathrm{m})$ fractions were obtained using an acid-washed rubber-free plastic syringe and a DISMIC disposable polyethersulfone membrane filter unit (Advantec, Japan). Then, the aliquot was spiked with the fluorescent substrate at a final concentration of $1 \mu \mathrm{M}$, and fluorescence was measured again (initial measurement). The aliquots were incubated in a dark incubator 
Table 1. List of sampling sites.

\begin{tabular}{|c|c|c|c|c|c|c|c|c|}
\hline \multirow[t]{2}{*}{ Cruise } & \multirow[t]{2}{*}{ Station } & \multirow[t]{2}{*}{ Latitude } & \multirow[t]{2}{*}{ Longitude } & \multirow[t]{2}{*}{$\begin{array}{r}\text { SCM } \\
\text { depth }(m)\end{array}$} & \multicolumn{2}{|c|}{$\begin{array}{c}\text { Water } \\
\text { temperature }\left({ }^{\circ} \mathrm{C}\right)\end{array}$} & \multicolumn{2}{|c|}{$\begin{array}{c}\text { Chlorophyll } a \\
\text { concentration }\left(\mu \mathrm{g} \mathrm{L}^{-1}\right)\end{array}$} \\
\hline & & & & & $10 \mathrm{~m}$ & SCM & $10 \mathrm{~m}$ & $\mathrm{SCM}$ \\
\hline \multirow[t]{22}{*}{ KH-11-10 } & 1 & $23^{\circ} \mathrm{N}$ & $155^{\circ} \mathrm{E}$ & 134 & 26.9 & 19.6 & 0.038 & 0.149 \\
\hline & 2 & $23^{\circ} \mathrm{N}$ & $160^{\circ} \mathrm{E}$ & 116 & 26.8 & 20.2 & 0.046 & 0.228 \\
\hline & 3 & $23^{\circ} \mathrm{N}$ & $165^{\circ} \mathrm{E}$ & 119 & 27.4 & 24.1 & 0.046 & 0.221 \\
\hline & 4 & $23^{\circ} \mathrm{N}$ & $170^{\circ} \mathrm{E}$ & 98 & 26.2 & 19.4 & 0.047 & 0.274 \\
\hline & $4 B$ & $23^{\circ} \mathrm{N}$ & $175^{\circ} \mathrm{E}$ & 109 & 26.3 & 22.4 & 0.058 & 0.204 \\
\hline & 5 & $23^{\circ} \mathrm{N}$ & $180^{\circ}$ & 119 & 26.4 & 23.4 & 0.048 & 0.228 \\
\hline & 6 & $23^{\circ} \mathrm{N}$ & $170^{\circ} \mathrm{W}$ & 110 & 25.3 & 23.3 & 0.098 & 0.254 \\
\hline & 7 & $23^{\circ} \mathrm{N}$ & $165^{\circ} \mathrm{W}$ & 97 & 25.1 & 24.1 & 0.121 & 0.303 \\
\hline & 8 & $22^{\circ} 46^{\prime} \mathrm{N}$ & $158^{\circ} 06^{\prime} \mathrm{W}$ & 105 & 24.2 & 23.8 & 0.143 & 0.163 \\
\hline & 9 & $13^{\circ} \mathrm{N}$ & $148^{\circ} \mathrm{W}$ & 73 & 25.2 & 21.6 & 0.122 & 0.353 \\
\hline & 10 & $7^{\circ} \mathrm{N}$ & $142^{\circ} \mathrm{W}$ & 71 & 27.4 & 24.6 & 0.102 & 0.294 \\
\hline & 11 & $0^{\circ}$ & $135^{\circ} \mathrm{W}$ & 40 & 24.2 & 24.0 & 0.251 & 0.348 \\
\hline & 12 & $7^{\circ} 30^{\prime} \mathrm{S}$ & $127^{\circ} 30^{\prime} \mathrm{W}$ & 89 & 25.2 & 22.1 & 0.141 & 0.238 \\
\hline & 13 & $15^{\circ} \mathrm{S}$ & $120^{\circ} \mathrm{W}$ & 65 & 25.5 & 23.6 & 0.126 & 0.261 \\
\hline & 14 & $20^{\circ} \mathrm{S}$ & $120^{\circ} \mathrm{W}$ & 150 & 25.9 & 23.3 & 0.115 & 0.200 \\
\hline & 15 & $23^{\circ} \mathrm{S}$ & $120^{\circ} \mathrm{W}$ & 174 & 25.2 & 21.5 & 0.065 & 0.185 \\
\hline & 16 & $26^{\circ} 30^{\prime} \mathrm{S}$ & $120^{\circ} \mathrm{W}$ & 177 & 24.4 & 19.4 & 0.023 & 0.180 \\
\hline & 17 & $30^{\circ} \mathrm{S}$ & $120^{\circ} \mathrm{W}$ & 162 & 22.6 & 16.3 & 0.021 & 0.217 \\
\hline & 19 & $30^{\circ} \mathrm{S}$ & $100^{\circ} \mathrm{W}$ & 126 & 21.7 & 17.4 & 0.035 & 0.220 \\
\hline & 20 & $26^{\circ} 30^{\prime} \mathrm{S}$ & $100^{\circ} \mathrm{W}$ & 172 & 23.5 & 18.4 & 0.025 & 0.219 \\
\hline & 21 & $23^{\circ} \mathrm{S}$ & $100^{\circ} \mathrm{W}$ & 163 & 23.9 & 18.9 & 0.024 & 0.208 \\
\hline & 22 & $20^{\circ} \mathrm{S}$ & $100^{\circ} \mathrm{W}$ & 151 & 24.3 & 19.6 & 0.098 & 0.213 \\
\hline \multirow[t]{18}{*}{ KH-12-3 } & 1 & $46^{\circ} 55^{\prime} \mathrm{N}$ & $160^{\circ} \mathrm{E}$ & 43 & 8.3 & 1.9 & 0.453 & 0.824 \\
\hline & 2 & $43^{\circ} 30^{\prime} \mathrm{N}$ & $160^{\circ} \mathrm{E}$ & 31 & 12.1 & 11.2 & 0.627 & 0.645 \\
\hline & 3 & $40^{\circ} \mathrm{N}$ & $160^{\circ} \mathrm{E}$ & 28 & 16.3 & 13.6 & 0.615 & 0.589 \\
\hline & 4 & $37^{\circ} 30^{\prime} \mathrm{N}$ & $160^{\circ} \mathrm{E}$ & 93 & 20.5 & 16.3 & 0.145 & 0.155 \\
\hline & 5 & $35^{\circ} \mathrm{N}$ & $160^{\circ} \mathrm{E}$ & 63 & 22.6 & 18.9 & 0.073 & 0.776 \\
\hline & 6 & $33^{\circ} \mathrm{N}$ & $160^{\circ} \mathrm{E}$ & 82 & 23.6 & 17.3 & 0.076 & 0.440 \\
\hline & 7 & $30^{\circ} \mathrm{N}$ & $160^{\circ} \mathrm{E}$ & 87 & 27.0 & 17.8 & 0.054 & 0.519 \\
\hline & 8 & $25^{\circ} \mathrm{N}$ & $160^{\circ} \mathrm{E}$ & 137 & 28.6 & 18.6 & 0.048 & 0.384 \\
\hline & 9 & $20^{\circ} \mathrm{N}$ & $160^{\circ} \mathrm{E}$ & 126 & 29.2 & 22.8 & 0.060 & 0.416 \\
\hline & 10 & $15^{\circ} \mathrm{N}$ & $160^{\circ} \mathrm{E}$ & 122 & 29.3 & 26.2 & 0.052 & 0.366 \\
\hline & 11 & $10^{\circ} \mathrm{N}$ & $160^{\circ} \mathrm{E}$ & 128 & 29.1 & 24.2 & 0.046 & 0.318 \\
\hline & 12 & $20^{\circ} \mathrm{N}$ & $148^{\circ} \mathrm{E}$ & 129 & 29.0 & 20.6 & 0.101 & 0.282 \\
\hline & 13 & $30^{\circ} \mathrm{N}$ & $144^{\circ} 50^{\prime} \mathrm{E}$ & 87 & 27.3 & 18.3 & 0.073 & 0.557 \\
\hline & 14 & $24^{\circ} \mathrm{N}$ & $143^{\circ} 12^{\prime} \mathrm{E}$ & 88 & 28.6 & 25.8 & 0.068 & 0.328 \\
\hline & 15 & $28^{\circ} \mathrm{N}$ & $138^{\circ} \mathrm{E}$ & 80 & 27.4 & 20.6 & 0.077 & 0.792 \\
\hline & 16 & $31^{\circ} \mathrm{N}$ & $134^{\circ} 04^{\prime} \mathrm{E}$ & 105 & 27.4 & 19.7 & 0.059 & 0.382 \\
\hline & 17 & $32^{\circ} 15^{\prime} \mathrm{N}$ & $133^{\circ} 23^{\prime} \mathrm{E}$ & 80 & 28.6 & 22.6 & 0.077 & 0.424 \\
\hline & 18 & $33^{\circ} 05^{\prime} \mathrm{N}$ & $133^{\circ} 40^{\prime} \mathrm{E}$ & 43 & 28.3 & 21.0 & 0.236 & 1.039 \\
\hline
\end{tabular}

at the temperature of the $10 \mathrm{~m}$ depth at the sampling site. Fluorescence was measured four times over $12 \mathrm{~h}$, including the initial measurement, and the hydrolysis rate was calculated from the slope of the regression line of the fluorescent probe 4-methylumbelliferone concentration against incubation time. When the coefficient of determination was lower than 0.8 , we judged that the regression was unsuccessful and the figure was excluded from a data set. Autoclaved filtered seawater spiked with the same concentration of the substrate was used as a blank, and in most cases, hydrolysis of the blank was insignificant. As described in the results section, the half-saturation constant of phosphatase was around or below $1 \mu \mathrm{M}$. Thus, although the hydrolysis rate at $1 \mu \mathrm{M} \mathrm{flu}-$ orescent substrate was somewhat lower than the maximum hydrolysis rate, it is indicative of the potential rate of ester hydrolysis.

Fluorescence intensity was measured using a spectrofluorometer RF-1500 (Shimadzu, Japan). The excitation and emission wavelengths were 359 and $449 \mathrm{~nm}$, respectively, and slit widths were set to $10 \mathrm{~nm}$. A standard curve was 
obtained at every time point by using solutions of 0 to $50 \mathrm{nM}$ 4-methylumbelliferone (Sigma Aldrich) in filtered seawater.

Since one molecule of Bis-MUP can release two molecules of 4-methylumbelliferone, the latter of which is catalyzed by monoesterase, not by diesterase, the present method can overestimate DEA at most by 2 times. However, when correcting for the second hydrolysis using kinetic parameters for monoesters (see below), the contribution of the hydrolysis of the monoester was $<16 \%$ at all the stations, and $<5 \%$ except at one station (station 9). And as described in the results section, the half-saturation constant of diesterase was sometimes higher than $1 \mu \mathrm{M}$. Therefore, the present hydrolysis rate measured at $1 \mu \mathrm{M}$ of the substrate should be interpreted as a potential hydrolysis rate, and would be difficult to directly compare with the monoesterase activity.

\subsection{Kinetics assay}

Kinetic assay experiments were conducted at five stations during the KH-12-3 cruise (Fig. 1). Samples were prepared in similar ways as for the activity assay described above, but the fluorescent substrates were added at three different concentrations $(0.05,0.1$, and $1 \mu \mathrm{M})$. Hydrolysis rates were plotted against initial substrate concentrations, the MichaelisMenten function was fitted using software OriginPro 8.5 (OriginLab, USA), and all the statistic tests were performed. Kinetic parameters were presented only when the fitting parameters converged successfully. The initial substrate concentration was calculated as a sum of the added fluorescent substrate and ambient LDOP concentration based on the assumption that the reactivity was similar between the two substrates.

\subsection{SRP, LDOP, and DOP determination}

Seawater samples for the determination of SRP and DOP were frozen at $-20^{\circ} \mathrm{C}$ on board. LDOP samples were frozen at $-20^{\circ} \mathrm{C}$ after an enzymatic treatment on board. The enzymatic treatment was based on the procedure of Hashihama et al. (2013), which used a commercially-available alkaline phosphatase from Escherichia coli and adopted an azide treatment to remove the biological influence that occurs during DOP hydrolysis. All the frozen samples were analyzed ashore.

The SRP concentration was determined by using a highly sensitive colorimeter equipped with a liquid waveguide capillary cell (LWCC) (Hashihama et al., 2009). Phosphate-free seawater, prepared by the MAGIC procedure (Karl and Tien, 1992), was used as the blank and standard matrix. The detection limit of this analytical system was $3 \mathrm{nM}$, and data below the detection limit were regarded as $3 \mathrm{nM}$. Since SRP concentrations in the equatorial upwelling area or the transition area from subarctic and subtropical gyre could not be determined due to over the detection range of the sensitive
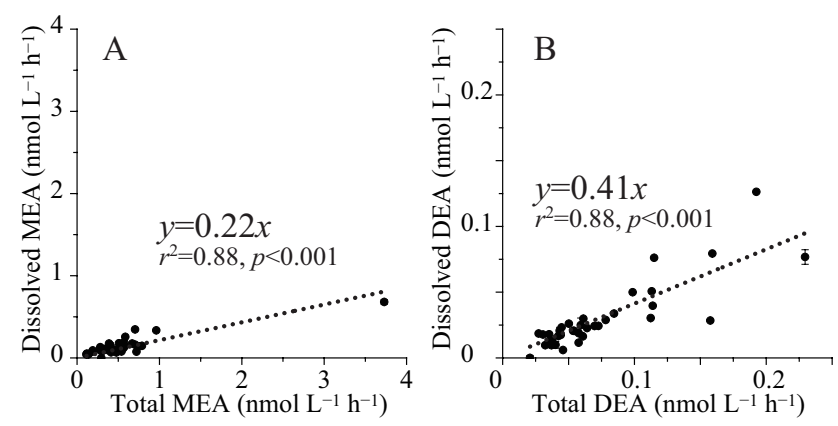

Fig. 2. Phosphate esterase activities in the dissolved $(<0.2 \mu \mathrm{M})$ fraction vs. those in the total (unfiltered) fraction. (A) Monoesterase activities and (B) diesterase activities.

method, the SRP concentrations in these areas were determined by the conventional colorimetry using an AutoAnalyzer (TRAACS 2000, Bran+Luebbe). The sensitive SRP method was also used for LDOP determination (Hashihama et al., 2013). The LDOP concentration was derived from the difference between two measured SRP concentrations, with and without the enzymatic treatment. For the duplicate LDOP samples collected during the KH-12-3 cruise, mean concentrations were calculated and shown in the present paper. As in the case of SRP, LDOP data below $3 \mathrm{nM}$ were regarded as $3 \mathrm{nM}$.

DOP samples were treated with acid-persulfate oxidation (Hansen and Koroleff, 1999), and then the SRP concentration in the oxidized sample was measured by the sensitive method described above. For this measurement, $3 \% \mathrm{NaCl}$ solution was used as the blank and standard matrix. The DOP concentration was derived from the difference between the two measured SRP concentrations, with and without the oxidative treatment.

\section{Results}

\subsection{MEA and DEA potential}

In the open ocean, most of the phosphate esterase activity is associated with microbes. Thus, an index of microbial biomass is necessary to standardize the enzymatic activities. In the present study, the chlorophyll $a$ concentration was used as an index of microbial biomass, on the assumption that the heterotrophic bacterial biomass is largely proportional to the autotrophic biomass, although there have been more studies in which bacterial cell concentration or carbon biomass was used to normalize enzymatic activities in the ocean. Hydrolysis activity in the present study is expressed as a chlorophyll-specific value (nmol $\left.\mu \mathrm{g}^{-1} \mathrm{chl} a \mathrm{~h}^{-1}\right)$. Note that this does not imply that hydrolysis activity was associated only with autotrophic microbes. In a previous study conducted in the Atlantic Ocean, the denominator of the normalization process (phytoplankton biomass converted 


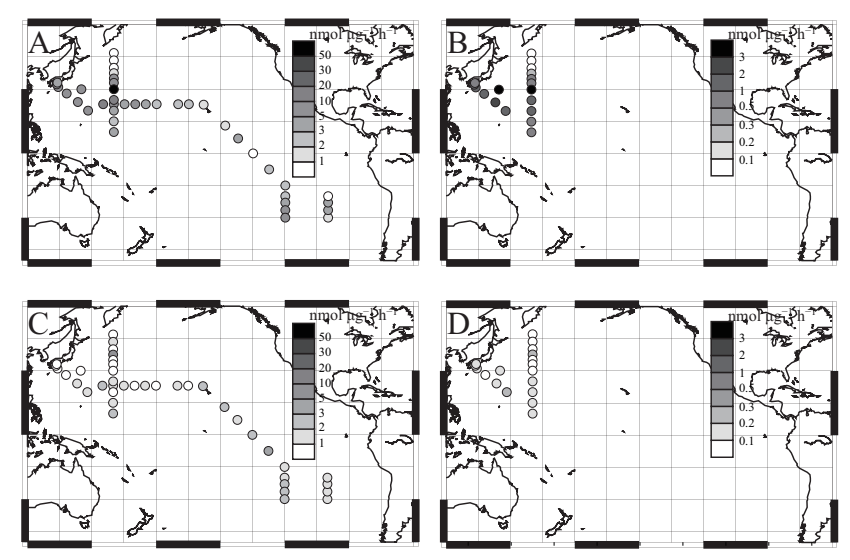

Fig. 3. Volumetric phosphate monoesterase $(\mathbf{A}, \mathbf{C})$ and diesterase (B, D) activities normalized to chlorophyll $a$ concentration throughout the Pacific Ocean. (A) and (B) are from the $10 \mathrm{~m}$ depth, and (C) and (D) are from the subsurface chlorophyll maximum layer.

from chlorophyll $a$ concentration, bacterial carbon biomass, or sum of the two) did not significantly affect data patterns (Mather et al., 2008).

For both monoesterase and diesterase, activities in the total and dissolved fractions correlated very well with each other (Fig. 2). The slope of the regression line was $0.22 \pm 0.01$ and $0.41 \pm 0.03$ for monoesterase and diesterase, respectively, and this value was not significantly different after removing the outlier (total MEA $>3 \mathrm{nmol} \mathrm{L}^{-1} \mathrm{~h}^{-1}$ ). The average proportion of the dissolved fraction to the total fraction was $29 \pm 11 \%$ (13-49\%, median: $30 \%)$ and $38 \pm 15 \%(13-$ $49 \%$, median: $37 \%$ ) for monoesterase and diesterase, respectively. Pairwise Wilcoxon rank sum tests showed that the proportion of the dissolved fraction was significantly higher $(p<0.001)$ for DEA than for MEA. Additionally, the proportion of MEA in the dissolved fraction was significantly higher $(p<0.01)$ at $10 \mathrm{~m}$ than that at SCM, while the difference was insignificant $(p>0.05)$ for DEA. Hereafter, "enzymatic activity" means activity in the total fraction, unless otherwise specified.

Chlorophyll-specific MEA and DEA at $10 \mathrm{~m}$ depth showed similar distribution patterns, which peaked around $30^{\circ} \mathrm{N}$ in the western North Pacific (Fig. 3). Enzymatic activities were relatively low in the other subtropical regions, but higher than that at subarctic stations. Within the south subtropical Pacific gyre, MEA was slightly higher around $25^{\circ} \mathrm{S}$, $120^{\circ} \mathrm{W}$ than at the other stations. A closer look at the surface distribution maps of MEA and DEA revealed that the two enzymatic activity patterns were different in some locations. First, the peak of MEA was much steeper than that of DEA; MEA at $30^{\circ} \mathrm{N}, 160^{\circ} \mathrm{E}$ was more than three times higher than at all the other stations. Second, the position of the peak was different for the two enzymes; the peak of DEA was further west at $30^{\circ} \mathrm{N}, 145^{\circ} \mathrm{E}$.
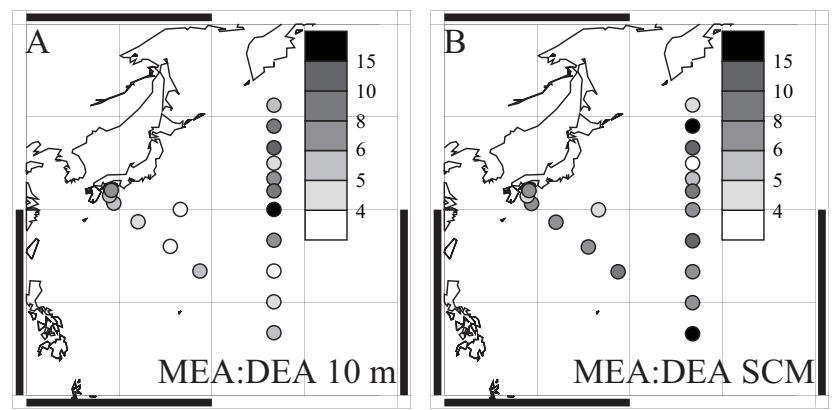

Fig. 4. The ratio of phosphate monoesterase activity to diesterase activity at $10 \mathrm{~m}$ depth (A) and subsurface chlorophyll maximum layer (B) during the $\mathrm{KH}-12-3$ cruise.

Chlorophyll-specific MEA and DEA at SCM were lower than that at the surface but detectable throughout the Pacific Ocean (Fig. 3). There were no discernible distribution patterns for either MEA or DEA, except that both enzymatic activities were lower to the north of $30^{\circ} \mathrm{N}$. Here it is notable that the hydrolysis activity at SCM is likely somewhat overestimated because the samples from $10 \mathrm{~m}$ and SCM were incubated at the same temperature $(10 \mathrm{~m}$ temperature at the station). On the basis of previously reported $Q_{10}$ values of phosphatase between 1.5 and 2.0 (Huber and Kidby, 1984) and at most $10.0^{\circ} \mathrm{C}$ temperature difference between $10 \mathrm{~m}$ and SCM, the activity can be overestimated at most by two times. Therefore, the difference of chlorophyll $a$ specific activities between the two depths could be even larger than that assayed in the present study.

In general, since the areas with high phosphate esterase specific activities are characterized by a low chlorophyll $a$ concentration, absolute values of MEA and DEA (not normalized by chlorophyll $a$ concentration) showed smaller horizontal variations (data not shown). Similarly, differences in volumetric esterase activities between $10 \mathrm{~m}$ and SCM were relatively small compared with those in specific activities. These observations demonstrate that the volumetric potential to hydrolyze phosphate esters does not significantly vary as the water temperature or nutrient and light environments vary horizontally and vertically throughout the open water of the Pacific Ocean and that microbial hydrolysis of organic phosphate esters is a ubiquitous phenomenon throughout the euphotic zone of the Pacific Ocean.

MEA was more than three times as high (3.1 to 19.4 times at $10 \mathrm{~m}, 4.5$ to 18.2 times at SCM) as DEA at all the stations during the KH-12-3 cruise (Fig. 4), suggesting that the phosphate monoester was a much more important phosphorus source for microbes in the surface waters than the diester. The ratio of MEA to DEA was significantly higher at $10 \mathrm{~m}$ than at SCM (pairwise Wilcoxon test, $p<0.05$ ), suggesting that the surface communities were more dependent on monoester than the deeper communities. 

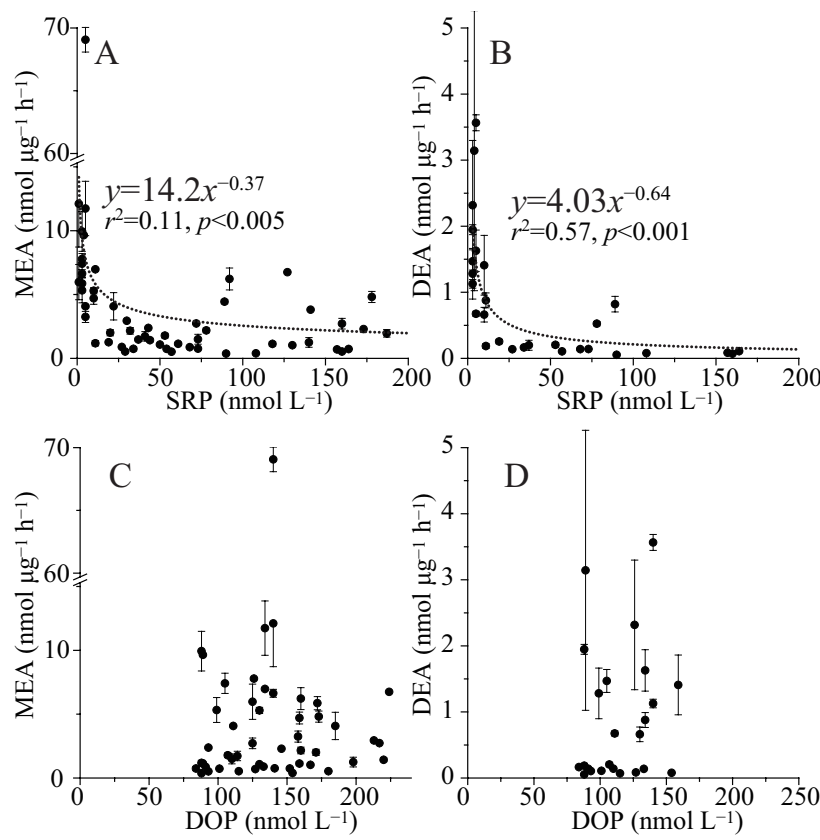

Fig. 5. Chlorophyll $a$-normalized volumetric phosphate monoesterase $(\mathbf{A}, \mathbf{C})$ and diesterase $(\mathbf{B}, \mathbf{D})$ activities plotted against $\operatorname{SRP}(\mathbf{A}, \mathbf{B})$ and total DOP $(\mathbf{C}, \mathbf{D})$ concentrations. Error bars indicate standard deviations of triplicate measurements.

Chlorophyll $a$ specific MEA and DEA sensitively responded to ambient SRP concentration in the subtropical gyres (Fig. 5a and b). The relationship between the enzymatic activity and SRP concentration was successfully expressed as a power function, and the scaling exponent was $-0.37 \pm 0.15$ and $-0.64 \pm 0.09$ for MEA and DEA, respectively $(p<0.01)$. These relationships were similarly significant when correcting for the effect of incubation temperature using a $Q_{10}$ value of 1.5 or 2.0 (Huber and Kidby, 1984 ) and the scaling exponent was not significantly different. Data points over the fitting curve for MEA between 100 and $200 \mathrm{nM}$ of SRP (Fig. 5a) corresponded to the samples collected at $10 \mathrm{~m}$ in the south subtropical gyre (see also Fig. 2). On the other hand, neither MEA nor DEA showed any significant relationship against total DOP concentrations (Fig. 5c and d).

\subsection{MEA and DEA kinetics}

Kinetics parameters were obtained for MEA at all the five stations, while the curve fitting was successful for 6 out of 10 samples for DEA (Table 2), which is due to barely detectable release of fluorescent moieties from Bis-MUP spiked at low concentrations $(0.05 \mu \mathrm{M})$.

In the samples collected from $10 \mathrm{~m}$ depth, both SRP and LDOP concentrations were lower than $10 \mathrm{nM}$ except at station (Stn.) 1, while the kinetics parameters of MEA varied spatially. At Stn. 1 located within the subarctic gyre, where
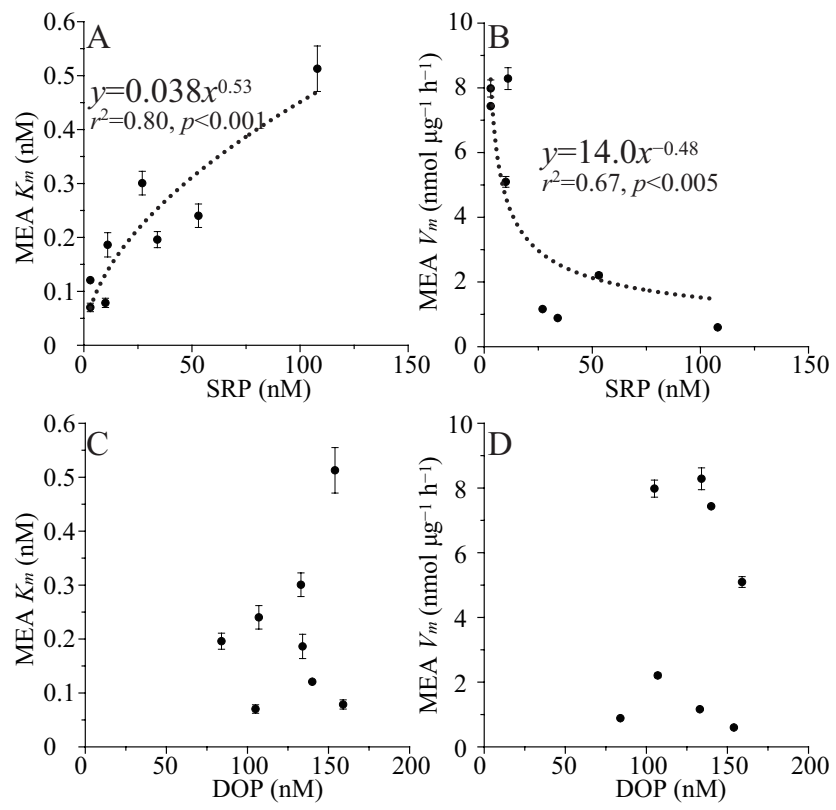

Fig. 6. Half-saturation constants (A, C) and chlorophyll anormalized maximum hydrolysis rates $(\mathbf{B}, \mathbf{D})$ of phosphate monoesterase plotted against SRP $(\mathbf{A}, \mathbf{B})$ and total DOP $(\mathbf{C}, \mathbf{D})$ concentrations. Error bars indicate $95 \%$ confidence intervals of curve fitting.

surface SRP was replete, the half-saturation constant $\left(K_{\mathrm{m}}\right)$ was significantly higher, and the chlorophyll-specific maximum hydrolysis rate $\left(V_{\mathrm{m}}\right)$ was lower than that at the other stations. Among the other four stations, the kinetics parameters at $10 \mathrm{~m}$ depth were relatively similar to each other, but both $K_{\mathrm{m}}$ and $V_{\mathrm{m}}$ values were higher at $\operatorname{Stn} .5$ and $V_{\mathrm{m}}$ was significantly lower at Stn. 9 than at the other three stations. The DEA kinetics parameters at $10 \mathrm{~m}$ fluctuated greatly, sometimes with wide intervals of significance. At Stn. 17, both $K_{\mathrm{m}}$ and $V_{\mathrm{m}}$ values were lower than that at the other stations.

In the samples collected from SCM, the SRP concentration was obviously higher than that from the $10 \mathrm{~m}$ depth, while the LDOP concentration was more similar between the two different depths. Overall, the $K_{\mathrm{m}}$ value was higher for SCM samples than for samples at the $10 \mathrm{~m}$ depth of the same station, while $V_{\mathrm{m}}$ values were lower in samples from SCM. A comparison among the different stations demonstrated that $K_{\mathrm{m}}$ values decreased toward the lower latitudes, while $V_{\mathrm{m}}$ values increased at the same time. Again, DEA kinetics parameters were highly variable, and there was no obvious trend except that both $K_{\mathrm{m}}$ and $V_{\mathrm{m}}$ were strikingly low at Stn. 1.

For both $K_{\mathrm{m}}$ and $V_{\mathrm{m}}$ of MEA, the power function against SRP concentration was well fitted $(p<0.01$, Fig. 6a and b). The scaling exponent was $0.53 \pm 0.11$ and $-0.48 \pm 0.16$ for $K_{\mathrm{m}}$ and $V_{\mathrm{m}}$, respectively. When $V_{\mathrm{m}}$ was not normalized to the chlorophyll $a$ concentration, the relationship was insignificant ( $p>0.05$, data not shown). When correcting the 
Table 2. Half-saturation constant $K_{\mathrm{m}}$ and maximum hydrolysis rate $V_{\mathrm{m}}$ of phosphate monoesterase and diesterase calculated from the results of kinetic assay experiments. Note that $V_{\mathrm{m}}$ is normalized to chlorophyll $a$ concentration. N.D. for kinetic parameters means that no value was obtained because of unsuccessful fitting; N.D. for LDOP means no data were obtained. The values with asterisks were obtained by the conventional colorimetric method.

\begin{tabular}{|c|c|c|c|c|c|c|c|}
\hline & & \multicolumn{2}{|c|}{ Monoesterase } & \multicolumn{2}{|c|}{ Diesterase } & \multirow[b]{2}{*}{$\mathrm{SRP}(\mathrm{nM})$} & \multirow[b]{2}{*}{ LDOP (nM) } \\
\hline & & $K_{\mathrm{m}}(\mu \mathrm{M})$ & $V_{\mathrm{m}}\left(\mathrm{nmol} \mu \mathrm{g}^{-1} \mathrm{~h}^{-1}\right)$ & $K_{\mathrm{m}}(\mu \mathrm{M})$ & $V_{\mathrm{m}}\left(\mathrm{nmol} \mu \mathrm{g}^{-1} \mathrm{~h}^{-1}\right)$ & & \\
\hline \multirow{5}{*}{$10 \mathrm{~m}$} & Stn. 1 & $0.39 \pm 0.031$ & $0.36 \pm 0.011$ & & N.D. & $810 *$ & N.D. \\
\hline & Stn. 5 & $0.19 \pm 0.022$ & $8.29 \pm 0.338$ & & N.D. & 11 & 6 \\
\hline & Stn. 9 & $0.08 \pm 0.008$ & $5.10 \pm 0.166$ & $3.81 \pm 0.253$ & $6.78 \pm 0.358$ & 10 & 6 \\
\hline & Stn. 12 & $0.12 \pm 0.001$ & $7.43 \pm 0.012$ & $7.74 \pm 10.94$ & $9.85 \pm 12.36$ & 3 & 3 \\
\hline & Stn. 17 & $0.07 \pm 0.008$ & $7.98 \pm 0.263$ & $0.53 \pm 0.001$ & $2.25 \pm 0.002$ & 3 & 3 \\
\hline \multirow{5}{*}{ SCM } & Stn. 1 & $0.59 \pm 0.014$ & $0.27 \pm 0.003$ & $0.92 \pm 0.120$ & $0.07 \pm 0.005$ & $1850^{*}$ & N.D. \\
\hline & Stn. 5 & $0.52 \pm 0.038$ & $0.60 \pm 0.020$ & & N.D. & 108 & 20 \\
\hline & Stn. 9 & $0.30 \pm 0.022$ & $1.16 \pm 0.030$ & $2.87 \pm 0.190$ & $0.54 \pm 0.027$ & 27 & 3 \\
\hline & Stn. 12 & $0.24 \pm 0.021$ & $2.21 \pm 0.068$ & $3.87 \pm 3.078$ & $0.99 \pm 0.632$ & 53 & 3 \\
\hline & Stn. 17 & $0.20 \pm 0.015$ & $0.89 \pm 0.023$ & & N.D. & 34 & 4 \\
\hline
\end{tabular}

$V_{\mathrm{m}}$ values at SCM using $Q_{10}$ values of 1.5 or 2.0 (Huber and Kidby, 1984), the relationship was significant $(p<0.01$, data not shown) again, and the scaling value was $-0.51 \pm 0.17$ and $-0.53 \pm 0.18$, respectively. The fitting against total DOP concentration was not successful (Fig. 6c and d). The data range of LDOP was too narrow to examine the correlations with MEA kinetics parameters (data not shown). The kinetics parameters of DEA did not show any significant relationship with SRP, LDOP or total DOP concentration (data not shown), which may be due to wide errors associated with the parameters.

The potential turnover times of the phosphate monoester, obtained by dividing $K_{\mathrm{m}}$ by $V_{\mathrm{m}}$ (Labry et al., 2005), were in the range of 5 to 100 days, and were longer at SCM than at $10 \mathrm{~m}$ (Table 3). The turnover time was obviously longer at Stn. 1, and was similar among the other stations. For phosphate diesters, a similar trend was also observed, although some values were lacking because of poor fitting to a Michaelis-Menten curve (see above). At both depths of all the stations, the turnover time was more than one order shorter for monoester than for diester.

\section{Discussion}

The present study elucidated the extensive distribution of the hydrolysis activities of phosphate monoesterase and diesterase by using artificial fluorogenic substrates. At five stations in the western North Pacific, kinetics parameters were estimated using three different concentrations of substrates, while at the other stations, the substrates were spiked at a single concentration of $1 \mu \mathrm{M}$. The present and previous studies (Table 2; Duhamel et al., 2011; Suzumura et al., 2012) showed that the half-saturation constants of MUP were around or below $1000 \mathrm{nM}$ throughout the open water of the Pacific Ocean, which validates interpreting the results of
Table 3. Turnover times (days) of phosphate monoesters and diesters calculated from kinetic parameters. N.D. means a value was not obtained because of unsuccessful fitting. For details on calculations, see the Materials and methods and the Results sections.

\begin{tabular}{rlrr}
\hline & & Monoesters & Diesters \\
\hline \multirow{4}{*}{$10 \mathrm{~m}$} & Stn. 1 & 99 & N.D. \\
& Stn. 5 & 13 & N.D. \\
& Stn. 9 & 11 & 390 \\
& Stn. 12 & 7 & 324 \\
& Stn. 17 & 5 & 128 \\
\hline \multirow{4}{*}{ SCM } & Stn. 1 & 112 & 652 \\
& Stn. 5 & 46 & N.D. \\
& Stn. 9 & 26 & 535 \\
& Stn. 12 & 16 & 575 \\
& Stn. 17 & 22 & N.D. \\
\hline
\end{tabular}

single-spike bioassay experiments as an index of the maximum hydrolysis rate of phosphate monoesters. This notion is supported by the present results that the hydrolysis rates of monoesters at $1 \mu \mathrm{M}$ of MUP corresponded to $>90 \%$ of the estimated maximum hydrolysis rate.

In contrast, care should be taken to interpret the results of DEA measurements in the present study, since the half-saturation constants were comparable or higher than $1000 \mathrm{nM}$ for Bis-MUP (Table 2). These data indicate that the results of single-spike experiments for DEA were considerably underestimated for the maximum hydrolysis rates. In addition, it should be taken into account that the DEA measured by the present method could be overestimated by at most $16 \%$ (see Materials and methods section). Therefore, the DEA measured by the present method should be considered a rough indicator of the potential of natural microbial assemblages to hydrolyze phosphate diesters. Bioassays 
using higher concentrations of substrates will be promising, although care should be taken to keep the background fluorescence as low as possible. Moreover, it is noteworthy that there have been no reports of phosphorus diester concentrations in the open ocean, including the present study. A few reports from coastal regions (Suzumura et al., 1998; Monbet et al., 2009) revealed that the diester concentrations were comparable with those of monoesters. If the concentrations of phosphate monoesters and diesters are comparable in the open ocean as well, diesters are biologically exchanged at a relatively lower rate compared to monoesters. This expectation is supported by the much longer potential turnover times of diesters obtained from kinetics studies (Table 3). As mentioned above, the diester hydrolysis rate at each substrate concentration and thus the estimated maximum hydrolysis rate could be overestimated to some degree. Therefore, the actual turnover time of DEA could be even longer, which reinforces the notion that the phosphate diester is a biologically more stable pool of dissolved organic phosphorus than the monoester.

The present study is the first to reveal the extensive distribution of alkaline phosphatase activities of both monoesterase and diesterase in the Pacific Ocean, including the north western subtropical area depleted with SRP at a nanomolar level (Hashihama et al., 2009). Previous phosphatase studies of the Pacific Ocean (Koike and Nagata, 1997; Duhamel et al., 2010, 2011) were primarily focused on the central and eastern Pacific, where $>10 \mathrm{nM}$ of SRP was detected. In the present study, the volumetric MEA values measured at the stations where $>10 \mathrm{nM}$ of SRP was detected were within the range mentioned in these previous reports. In the present study, both MEA and DEA were clearly enhanced wherein SRP concentrations were lower than $10 \mathrm{nM}$ (Fig. 4). Suzumura et al. (2012) reported that MEA in the western North Pacific was enhanced at an SRP concentration less than $20 \mathrm{nM}$. The present results extended their observations by adding data points with SRP concentration less than $10 \mathrm{nM}$. This trend was also observed in the Sargasso Sea (Lomas et al., 2010), where the surface SRP was exhausted down to $<3 \mathrm{nM}$. The highest monoester hydrolysis rate of $3.7 \mathrm{nMh}^{-1}$ or $69.1 \mathrm{nmol} \mathrm{mg}^{-1} \mathrm{chl} a \mathrm{~h}^{-1}$ was similar to that reported previously from the Sargasso Sea (Lomas et al., 2010; Orchard et al., 2010), suggesting a similar functional response of the total community MEA to ambient SRP concentration over different areas. In addition, the robust relationship between MEA and SRP concentration reinforces that MEA can be used as a highly sensitive index of scarcity of phosphorus nutrition down to the nanomolar level.

On the other hand, it should be noted that relatively high MEA was detected within the South Pacific subtropical gyre, where the surface SRP concentration exceeded $100 \mathrm{nM}$ (Figs. 3 and 5). The data points from the South Pacific subtropical gyre are apparent outliers from the fitting curve of MEA vs. SRP concentration. Moreover, incubation experiments conducted in the same area showed that the bacterial and primary productions there were not limited by phosphorus (Bonnet et al., 2008; Van Wambeke et al., 2008). One explanation for this relatively high MEA coincident with the absence of phosphorus limitation is the deficiency of available organic carbon, based on the hypothesis that another role of alkaline phosphatase in the deep ocean is to decompose the otherwise non-labile dissolved organic matter (Nausch and Nausch, 2004; Luo et al., 2011). Some studies have shown that deficiency of bioavailable organic carbon in the surface water of the subtropical South Pacific is one of the growthlimiting factors of cyanobacteria (Moisander et al., 2012) and heterotrophic bacteria (Van Wambeke et al., 2008). The hypothesis that MEA can supply bioavailable organic carbon from phosphoesters should be tested from uptake experiments using phosphoesters with isotopically labeled carbon. Nevertheless, the present results demonstrate that the diagnostic ability of MUF methods for community phosphorus limitations in the South Pacific is relatively limited, compared to that in the western North Pacific.

In contrast to the SRP, a decrease in total DOP did not suppress or enhance MEA or DEA (Fig. 5c and d). Here, it should be noted that DOP in natural water is a complex spectrum of various chemicals with different chemical properties (Suzumura et al., 1998; Kolowith et al., 2001; Monbet et al., 2009) and that the relative extent of fluctuation of DOP was smaller than that of SRP. Therefore, it is not clear that MEA and DEA are controlled only by product (inorganic phosphate) concentration and not by substrate concentration or other organic phosphorus sources, but it can be concluded that in the Pacific Ocean, the control of phosphate esterase activities by DOP is much weaker than that by inorganic phosphate.

The average percentage of MEA in the dissolved fraction (29\%) was very similar to previously reported values for other oligotrophic areas (Hoch and Bronk, 2007; Duhamel et al., 2011), although it varied within a considerable range (13$49 \%$ ), as in the previous studies. The proportion was lower at SCM than at $10 \mathrm{~m}$, which is apparently inconsistent with a previous report that the importance of dissolved extracellular enzymatic activities, including that of alkaline phosphatase to total activity, increased towards deeper water (Baltar et al., 2010). However, this report resulted from a survey throughout the whole water column, including the aphotic zone, and the samples for the photic zone were collected only from the depth of $100 \mathrm{~m}$. Therefore, the results from the present study suggest that the relationship between the proportion of MEA in the dissolved fraction and depth is different between the photic and aphotic zones. However, in the present study, the samples were taken only from two depths, which will be insufficient to discuss the vertical change in the fractionation of the enzymatic activities. Moreover, the partitioning of enzymatic activities are supposed to be associated with many factors, including abundance and composition of microbes, total areas of suspended organic particles and their physicochemical properties, grazing pressure and temperature. These are 
beyond the scope of the present study, and further studies will be needed to reveal the mechanism.

The proportion of the activity in the dissolved fraction was higher for DEA than for MEA (Fig. 2), which may be partly explained by the differential subcellular localization of the enzymes. To date, several families of alkaline phosphatases have been reported, among which PhoX and PhoD can hydrolyze both monoesters and diesters (Eder et al., 1996; Wu et al., 2007). Recent bioinformatics analysis of the marine metagenome database (Luo et al., 2009) revealed that the proportion of genes that are expected to encode extracellular enzymes was higher for PhoX than for PhoD or PhoA, which can hydrolyze only monoesters (Coleman, 1992). Although there should be a discrepancy between the amount of genes and activity of the encoded enzymes, it is notable that diesterase is more abundant in the extracellular fraction (not associated with cells) than monoesterase at the gene level. Analysis of the gene expression in the future can provide critical insights into this issue.

The differential substrate specificity among the different types of phosphatases may explain the slightly different distributions of MEA and DEA (Fig. 3). Taking marine cyanobacteria as an example, a putative gene encoding PhoX, which is expected to hydrolyze both monoesters and diesters, has been found only in limited strains such as Synechococcus sp. WH8012 (Adams et al., 2008) and Trichodesmium erythraeum IMS101 (Orchard et al., 2009). Taking into account drastic latitudinal and longitudinal variations in the microbial community composition in the western North Pacific (Sato et al., 2010), different repertoires of phosphatases among different microbial species may be a good explanation for the distribution of MEA and DEA, which should be examined by future gene expression analyses targeting $p h o A, p h o D$ and phoX with sufficiently high resolution of different taxa.

The half-saturation constants of MEA in the present study (Table 2) were reduced to 70 to $80 \mathrm{nM}$ at the stations where the surface SRP concentration was $<5 \mathrm{nM}$, which was comparable with values from other phosphate-depleted environments (Van Wambeke et al., 2002; Sebastián et al., 2004). This unequivocally demonstrates that the microbes are in severe competition for scarce phosphorus resources, and they adapt to the environments at a molecular level by producing the enzymes with sufficiently high affinity for the ambient substrate concentration. This conclusion is supported by a positive correlation between the half-saturation constants of MEA and SRP concentration (Fig. 6a), which was ambiguous in previous studies in the Pacific Ocean (Duhamel et al., 2011; Suzumura et al., 2012). Although it is not clear why the relationship was significant only for the present study, the range of SRP concentration may be important; the present study covered SRP concentrations ranging from 4 to $>150 \mathrm{nM}$. Conservatively, the relationship between the substrate affinity of MEA and SRP concentration may be confined to the western region of the North Pacific tropical gyre.
In contrast to the half-saturation constants, the maximum hydrolysis rate of MEA normalized by chlorophyll $a$ concentration was inversely proportional to the SRP concentration (Fig. 6b), which again suggests adaptation of the microbes to environments with a low phosphorus supply. Indeed, this relationship was observed across the Kuroshio current (Suzumura et al., 2012), while it was insignificant in other phosphate-depleted areas such as the Atlantic Ocean (Sebastián et al., 2004) or the central region of the North Pacific tropical gyre (Duhamel et al., 2011). We have no explanation for the observation that the inverse relationship was significant only in the western North Pacific. The possibility that usage of chlorophyll $a$ concentration as a denominator affected the result of the analyses could not be excluded and elucidation of major players of hydrolysis would be the next step of our study. Examination of MEA kinetic parameters of different microbial components, in association with the microbial community composition across this area, might provide insight.

Using two kinetic parameters, we calculated the potential turnover times of phosphate monoester and diester substrates. Here, it should be noted that the values were not based on actual hydrolysis rates in the environment because an extremely low concentration of LDOP (Table 2) impeded the direct calculation of in situ hydrolysis rates by using kinetic curves. Additionally, there were some other factors involved in the uncertainty of the turnover times, including substrate specificity and consumption of phosphate esters other than biologically catalyzed hydrolysis (e.g., direct uptake by microbes or absorption to sinking particles). Considering these caveats, we compared the turnover times of phosphate monoesters with those previously reported from oligotrophic waters. The values were within the range of the reported values from the western North Pacific (Suzumura et al., 2012) and lower than that from the central North and eastern South Pacific (Duhamel et al., 2011). The contrasting turnover times at the North and South Pacific subtropical gyres may reflect the differences in the SRP concentrations between the two gyres (Hashihama et al., 2009; Moutin et al., 2008). Actually, the slower turnover of phosphate monoesters at the higher concentration of SRP was observed when the scope was confined to the western North Pacific in the present study (Tables 2 and 3). On the other hand, the present values were a little longer than those from the Bay of Biscay (Labry et al., 2005) and the Mediterranean Sea (Van Wambeke et al., 2002), where the SRP concentration was lower than $10 \mathrm{nM}$ and the turnover times were sometimes shorter than 1 day. From the present study, the rationale for the slower turnover in the Pacific Ocean was unclear, but it may be associated with the difference in the composition of the microbial communities and/or the amount and composition of other forms of bioavailable organic phosphorus.

One of the most important results of the present study was the long turnover times of phosphate diesters (Table 3). To date, there have been no directly comparable data, except for 
some reports on the cycling of dissolved DNA (Paul et al., 1987; Brum, 2005), which is a polymer of phosphate diesters. There are some differences in the study areas, methodology and definition of fractionations of dissolved DNA between the two reports, but the results obtained were similar; dissolved DNA in seawater was cycled in $<1$ day. Although it should be examined to what degree the Bis-MUP fluorogenic substrate used in the present study represents the phosphate diester in natural seawater, we can envisage the biogeochemical cycling of phosphate diesters as follows. Phosphate diesters in surface seawater can be divided into two categories based on biological liability. One is a biologically labile fraction, cycled within a day, including dissolved DNA, while the other is a non-labile fraction that persists for $>100$ days, the composition of which has to be elucidated.

\section{Summary}

Within the euphotic layer of the Pacific Ocean, the activities of both phosphate monoesterase and diesterase were enhanced in response to a deficiency of inorganic phosphorus resources, except for in the South Pacific subtropical gyre, where relatively high hydrolytic activities and a high SRP concentration were simultaneously detected. Kinetic studies revealed that the microbes in the western North Pacific may adapt to the low-phosphorus environment at a molecular level; when the ambient SPR concentration was lower, the phosphate monoesterase had higher affinity and a maximum hydrolytic rate per microbial biomass. The potential turnover time of phosphate monoesters in the western North Pacific Ocean was 1 to 2 weeks, much shorter than that in the central North Pacific or the South Pacific, but slightly longer than that in other phosphate-depleted areas. Detecting much longer turnover times of phosphate diesters suggests that a significant fraction of phosphate diesters in the surface seawater is biologically refractory, except for a highly labile fraction such as dissolved DNA.

Future studies can be taken in two directions. One is a molecular biological analysis, including gene expression analysis, which can explain slightly different distributions of MEA and DEA, the higher proportion of DEA in the dissolved phase compared to MEA, and the relationship between enzymatic activities and the microbial community compositions. The other direction is to unravel the biogeochemical cycles of other forms of phosphorus compounds, such as phosphonate, polyphosphate and phosphite, the biogeochemical importance of which has begun to be recognized in recent years.

Acknowledgements. We thank all the crew and officers of the $\mathrm{R} / \mathrm{V}$ Hakuho-maru for their assistance in sample collection. We greatly appreciate the useful comments from H. Yamaguchi, Kochi University, on enzymatic assays for diesterase activities. Nutrient concentrations measured by the conventional method were kindly provided by H. Ogawa and his laboratory staff at Atmospheric and Ocean Research Institute, the University of Tokyo. This research was supported by JSPS grants nos. 22710003, 22710006, and 24710004 and Ministry of Education, Culture, Sports, Science and Technology (MEXT) Grants-in-Aid for Scientific Research on Innovative Areas (New Ocean Paradigm on Its Biogeochemistry, Ecosystem and Sustainable Use [NEOPS]: 24121003, 24121006).

Edited by: G. Herndl

\section{References}

Adams, M. M., Gómez-García, M. R., Grossman, A. R., and Bhaya, D.: Phosphorus deprivation responses and phosphonate utilization in a thermophilic Synechococcus sp. from microbial mats, J. Bacteriol., 190, 8171-8184, 2008.

Baltar, F., Arístegui, J., Gasol, J. M., Sintes, E., van Aken, H. M., and Herndl, G. J.: High dissolved extracellular enzymatic activity in the deep central Atlantic Ocean, Aquat. Microb. Ecol., 58, 287-302, 2010.

Björkman, K., Thomson-Bulldis, A. L., and Karl, D. M.: Phosphorus dynamics in the North Pacific Subtropical Gyre, Aquat. Microb. Ecol., 22, 185-198, 2000.

Bonnet, S., Guieu, C., Bruyant, F., Prášil, O., Van Wambeke, F., Raimbault, P., Moutin, T., Grob, C., Gorbunov, M. Y., Zehr, J. P., Masquelier, S. M., Garczarek, L., and Claustre, H.: Nutrient limitation of primary productivity in the Southeast Pacific (BIOSOPE cruise), Biogeosciences, 5, 215-225, doi:10.5194/bg-5-215-2008, 2008.

Brum, J. R.: Concentration, production and turnover of viruses and dissolved DNA pools at Stn ALOHA, North Pacific Subtropical Gyre, Aquat. Microb. Ecol., 41, 103-113, 2005.

Coleman, J. E.: Structure and mechanism of alkaline phosphatase, Annu. Rev. Bioph. Biom., 21, 441-483, 1992.

Duhamel, S., Dyhrman, S. T., and Karl, D. M.: Alkaline phosphatase activity and regulation in the North Pacific Subtropical Gyre, Limnol. Oceanogr., 55, 1414-1425, 2010.

Duhamel, S., Björkman, K. M., Van Wambeke, F., Moutin, T., and Karl, D. M.: Characterization of alkaline phosphatase activity in the North and South Pacific Subtropical Gyres: Implications for phosphorus cycling, Limnol. Oceanogr., 56, 1244-1254, 2011.

Dyhrman, S. T., Chappell, P. D., Haley, S. T., Moffett, J. W., Orchard, E. D., Waterbury, J. B., and Webb, E. A.: Phosphonate utilization by the globally important marine diazotroph Trichodesmium, Nature, 439, 68-71, 2006.

Eder, S., Shi, L., Jensen, K., Yamane, K., and Hulett, M.: A Bacillus subtilis secreted phosphodiesterase/alkaline phosphatase is the product of a Pho regulon gene, phoD, Microbiology, 142, 20412047, 1996.

Girault, M., Arakawa, H., and Hashihama, F.: Phosphorus stress of microphytoplankton community in the western subtropical North Pacific, J. Plankton. Res., 35, 146-157, 2013.

Hansen, H. P. and Koroleff, F.: Determination of nutrients, in: Methods of Seawater Analysis, Grasshoff, edited by: Kremling, K. and Ehrhardt, M., 3rd ed., Wiley, Weinheim, 159-228, 1999.

Hashihama, F., Furuya, K., Kitajima, S., Takeda, S., Takemura, T., and Kanda, J.: Macro-scale exhaustion of surface phosphate by dinitrogen fixation in the western North Pacific, Geophys. Res. Lett., 36, L003610, doi:10.1029/2008GL036866, 2009. 
Hashihama, F., Kinouchi, S., Suwa, S., Suzumura, M., and Kanda, J.: Sensitive determination of enzymatically labile dissolved organic phosphorus and its vertical profiles in the oligotrophic western North Pacific and East China Sea, J. Oceanogr., 69, 357367, 2013.

Hoch, M. P. and Bronk, D. A.: Bacterioplankton nutrient metabolism in the Eastern Tropical North Pacific, J. Exp. Mar. Biol. Ecol., 349, 390-404, 2007.

Hoppe, H.-G.: Significance of exoenzymatic activities in the ecology of brackish water: measurements by means of methylumbelliferyl-substrates, Mar. Ecol. Prog. Ser., 11, 299308, 1998.

Hoppe, H.-G.: Phosphatase activity in the sea, Hydrobiologia, 493, 187-200, 2003.

Huber, A. L. and Kidby, D. K.: An examination of the factors involved in determining phosphatase activities in estuarine water. 1: Analytical procedures, Hydrobiologia, 111, 3-11, 1984.

Ilikchyan, I. N., McKay, R. M. L., Kutovaya, O. A., Condon, R., and Bullerjahn, G. S.: Seasonal expression of the picocyanobacterial phosphonate transporter gene $p h n D$ in the Sargasso Sea, Front. Microbiol., 1, 135, doi:10.3389/fmicb.2010.00135, 2010.

Jørgensen, N. O. G. and Jacobsen, C. S.: Bacterial uptake and utilization of dissolved DNA, Aquat. Microb. Ecol., 11, 263-270, 1996.

Karl, D. M.: Phosphorus, the staff of life, Nature, 406, 31-32, 2000.

Karl, D. M. and Tien, G.: MAGIC: A sensitive and precise method for measuring dissolved phosphorus in aquatic environments, Limnol. Oceanogr., 37, 105-116, 1992.

Karl, D. M., Björkman, K. M., Dore, J. E., Fujieki, L., Hebel, D. V., Houlihan, T., Letelier, R. M., and Tupas, L. M.: Ecological nitrogen-phosphorus stoichiometry at station ALOHA, Deep-Sea Res. Pt. II, 48, 1529-1566, 2001.

Koike, I. and Nagata, T.: High potential activity of extracellular alkaline phosphatase in deep waters of the central Pacific, DeepSea Res. Pt. II, 44, 2283-2294, 1997.

Kolowith, L. C., Ingall, E. D., and Benner, R.: Composition and cycling of marine organic phosphorus, Limnol. Oceanogr., 46, 309-320, 2001.

Labry, C., Delmas, D., and Herbland, A.: Phytoplankton and bacterial alkaline phosphatase activities in relation to phosphate and DOP availability within the Gironde plume waters, J. Exp. Mar. Biol. Ecol., 318, 213-225, 2005.

Lomas, M. W., Burke, A. L., Lomas, D. A., Bell, D. W., Shen, C., Dyhrman, S. T., and Ammerman, J. W.: Sargasso Sea phosphorus biogeochemistry: an important role for dissolved organic phosphorus (DOP), Biogeosciences, 7, 695-710, doi:10.5194/bg-7695-2010, 2010.

Luo, H., Benner, R., Long, R. A., and Hu, J.: Subcellular localization of marine bacterial alkaline phosphatases, P. Natl. Acad. Sci. USA, 106, 21219-21223, 2009.

Luo, H., Zhang, H., Long, R. A., and Benner, R.: Depth distributions of alkaline phosphatase and phosphonate utilization genes in the North Pacific Subtropical Gyre, Aquat. Microb. Ecol., 62, 61-69, 2011.

Martínez, A., Osburne, M. S., Sharma, A. K., DeLong, E. F., and Chisholm, S. W.: Phosphite utilization by the marine picocyanobacterium Prochlorococcus MIT9301, Environ. Microbiol., 14, 1363-1377, 2012.
Mather, R. L., Reynolds, S. E., Wolff, G. A., Williams, R. G., Torres-Valdes, S., Woodward, E. M. S., Landolfi, A., Pan, X., Sanders, R., and Achterberg, E. P.: Phosphorus cycling in the North and South Atlantic Ocean subtropical gyres, Nature Geosci., 1, 439-443, 2008.

Moisander, P. H., Zhang, R., Boyle, E. A., Hewson, I., Montoya, J. P., and Zehr, J. P.: Analogous nutrient limitations in unicellular diazotrophs and Prochlorococcus in the Southern Pacific Ocean, ISME J., 6, 733-744, 2012.

Monbet, P., McKelvie, I. D., and Worsfold, P. J.: Dissolved organic phosphorus speciation in the waters of the Tamar estuary (SW England), Geochim. Cosmochim. Ac., 73, 1027-1038, 2009.

Moutin, T., Karl, D. M., Duhamel, S., Rimmelin, P., Raimbault, P., Van Mooy, B. A. S., and Claustre, H.: Phosphate availability and the ultimate control of new nitrogen input by nitrogen fixation in the tropical Pacific Ocean, Biogeosciences, 5, 95-109, doi:10.5194/bg-5-95-2008, 2008.

Nausch, M. and Nausch, G.: Bacterial utilization of phosphorus pools after nitrogen and carbon amendment and its relation to alkaline phosphatase activity, Aquat. Microb. Ecol., 37, 237-245, 2004.

Orchard, E. D., Webb, E. A., and Dyhrman, S. T.: Molecular analysis of the phosphorus starvation response in Trichodesmium spp., Environ. Microbiol., 11, 2400-2411, 2009.

Orchard, E. D., Ammerman, J. W., Lomas, M. W., and Dyhrman, S. T.: Dissolved inorganic and organic phosphorus uptake in Trichodesmium and the microbial community: The importance of phosphorus ester in the Sargasso Sea, Limnol. Oceanogr., 55, 1390-1399, 2010.

Paul, J, H. Jeffrey, W. H., and DeFlaun, M. F.: Dynamics of extracellular DNA in the marine environment, Appl. Environ. Microb., 53, 170-179, 1987.

Sato, M., Hashihama, F., Kitajima, S., Takeda, S., and Furuya, K.: Distribution of nano-sized Cyanobacteria in the western and central Pacific Ocean, Aquat. Microb. Ecol., 59, 273-282, 2010.

Sebastián, M., Arístegui, J., Montero, M. F., and Niell, F. X.: Kinetics of alkaline phosphatase activity, and effect of phosphate enrichment: a case study in the NW African upwelling region, Mar. Ecol.-Prog. Ser., 270, 1-13, 2004.

Suzumura, M., Ishikawa, K., and Ogawa, H.: Characterization of dissolved organic phosphorus in coastal seawater using ultrafiltration and phosphohydrolytic enzymes, Limnol. Oceanogr., 43, 1553-1564, 1998.

Suzumura, M., Hashihama, F., Yamada, N., and Kinouchi, S.: Dissolved phosphorus pools and alkaline phosphatase activity in the euphotic zone of the western North Pacific Ocean, Front. Microbiol., 3, 99, doi:10.3389/fmicb.2012.00099, 2012.

Van Wambeke, F., Christaki, U., Giannakourou, A., Moutin, T., and Souvemerzoglou, K.: Longitudinal and vertical trends of bacterial limitation by phosphorus and carbon in the Mediterranean Sea, Microb. Ecol., 43, 119-133, 2002.

Van Wambeke, F., Bonnet, S., Moutin, T., Raimbault, P., Alarcón, G., and Guieu, C.: Factors limiting heterotrophic bacterial production in the southern Pacific Ocean, Biogeosciences, 5, 833845, doi:10.5194/bg-5-833-2008, 2008.

Wu, J., Sunda, W., Boyle, E. A., and Karl, D. M.: Phosphate depletion in the western North Atlantic Ocean, Science, 289, 759-762, 2000 . 
Wu, J.-R., Shien, J.-H., Shieh, H. K., Hu, C.-C., Gong, S.-R., Chen, L.-Y., and Chang, P.-C.: Cloning of the gene and characterization of the enzymatic properties of the monomeric alkaline phosphatase (PhoX) from Pasteurella multocida strain X-73, FEMS Microbiol. Lett., 267, 113-120, 2007.
Yamguchi, H., Yamguchi, M., Fukami, K., Adachi, M., and Nishijima, T.: Utilization of phosphate diester by the marine diatom Chaetoceros ceratosporus, J. Plankton. Res., 27, 603-606, 2005. 